\title{
Two-Dimensional Fiber Positioning and Clamping Device for Product-Internal Microassembly
}

\author{
Vincent A. Henneken, Wouter P. Sassen, Wim van der Vlist, Wim H. A. Wien, \\ Marcel Tichem, and Pasqualina M. Sarro, Fellow, IEEE
}

\begin{abstract}
In this paper, we present a microelectromechanical systems-based two-degrees-of-freedom positioning device combined with a clamping structure for positioning and constraining an optical fiber. The fiber position can be controlled in the two directions perpendicular to the fiber axis using two specifically designed wedges that can be accurately moved in-plane. These wedges are positioned using in-plane thermal actuators. Actuation of a fiber tip greater than $25 \mu \mathrm{m}$ in-plane and $40 \mu \mathrm{m}$ out-of-plane is achieved with a displacement resolution better than $0.1 \mu \mathrm{m}$. After aligning the fiber the final position can be maintained by switching off the mechanical clamp, which also uses thermal actuators. The position of the fiber can be kept within $0.1 \mu \mathrm{m}$ after switching off the mechanical clamp and the positioning actuator. Fiber-to-fiber alignment experiments have been performed and the technique can be extended to fiber-to-laser alignment.

[2007-0248]
\end{abstract}

Index Terms-Mechanical clamping, microactuators, microassembly, thermal actuation.

\section{INTRODUCTION}

$\mathbf{P}$ ERFORMING microassembly tasks is technologically challenging due to part sizes and required positioning accuracies. Therefore, the microassembly of small parts can become a large part of the total product costs (sometimes up to $80 \%$ ), mainly due to the use of expensive machinery or the involvement of delicate handwork. This research focuses on an alternative method of microassembly using product-internal assembly functions. This method is applied in a two-stage process. In the first stage, coarse positioning of components is achieved using product-external assembly functions, typically by a (semi-) automatic production machine or a human operator. In the second stage, fine positioning is realized using the internal assembly functions of the previously assembled component. Using this method the assembly tolerances for the machine or human operator are much lower and therefore easier, faster, and cheaper to perform. Relaxing the tolerances

Manuscript received October 16, 2007; revised January 3, 2008. This work was supported by the Dutch government program IOP Precision Engineering as part of the Project IPT02310 Technologies for in-package optical fiber chip coupling. Subject Editor R. Syms.

V. A. Henneken, W. P. Sassen, and M. Tichem are with the Laboratory for Precision Manufacturing and Assembly, Delft University of Technology, 2628 CD Delft, The Netherlands (e-mail: M.Tichem@tudelft.nl).

W. van der Vlist, W. H. A. Wien, and P. M. Sarro are with the Delft Institute of Microsystems and Nanoelectronics, Delft University of Technology, 2628 CT Delft, The Netherlands.

Color versions of one or more of the figures in this paper are available online at http://ieeexplore.ieee.org.

Digital Object Identifier 10.1109/JMEMS.2008.918393

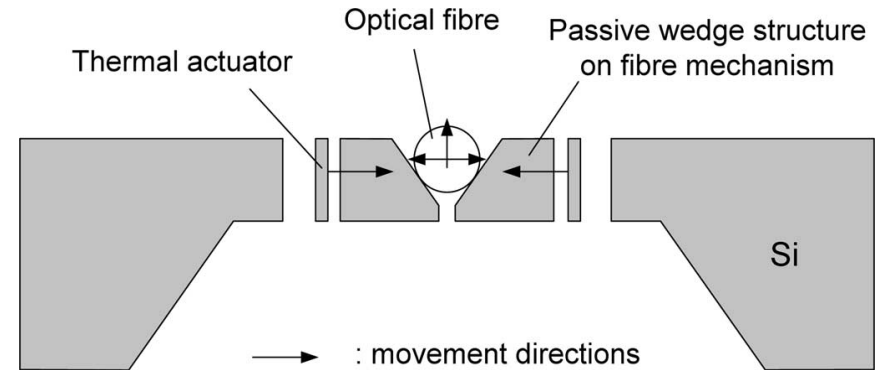

Fig. 1. Schematic cross-sectional view of the 2-DOF positioning device.

from several micrometers to approximately $20 \mu \mathrm{m}$ can increase the throughput of an assembly machine significantly and therefore lower the assembly costs [1].

The three main functions that apply for integration in the product are 1) controlled positioning of the component, 2) component position sensing, and 3) constraining the component in the final position. The coarse and fine positioning and fixation processes must work in conjunction to achieve an optimal overall result.

Microelectromechanical systems (MEMS) are suitable for creating devices capable of performing internal assembly functions because small dimensions and high accuracies can be achieved. In addition, manufacturing can be performed batchwise which enables cost reduction. The aim of this research is to develop an actuator for positioning and constraining a single mode optical fiber using a MEMS-based manufactured device.

The alignment requirement for a single mode optical fiber to a laser diode is typically $\pm 0.1 \mu \mathrm{m}$. Passive alignment approaches cannot achieve these tolerances and therefore active alignment is necessary. Several solutions for in-package fiber alignment can be found in literature. In [2] the fine alignment between two fibers is performed using a well-known electrothermal chevron type or V-beam actuator while the fixing is achieved by ultraviolet curing of an epoxy adhesive once the fibers are aligned. An alternative high-force MEMS electrothermal actuator configuration is demonstrated in [3], having a single-ended design allowing for clear access to the fiber tip. Both examples are capable of performing fiber tip movements in 1 DOF only. Multiple-axis solutions can also be found, such as a 2-D fiber alignment device with discrete piezoactuators capable of over $20 \mu \mathrm{m}$ displacements in both directions at up to $130 \mathrm{~V}$ [4]. This device however is not based on MEMS technology, and batchwise manufacturing therefore cannot be 


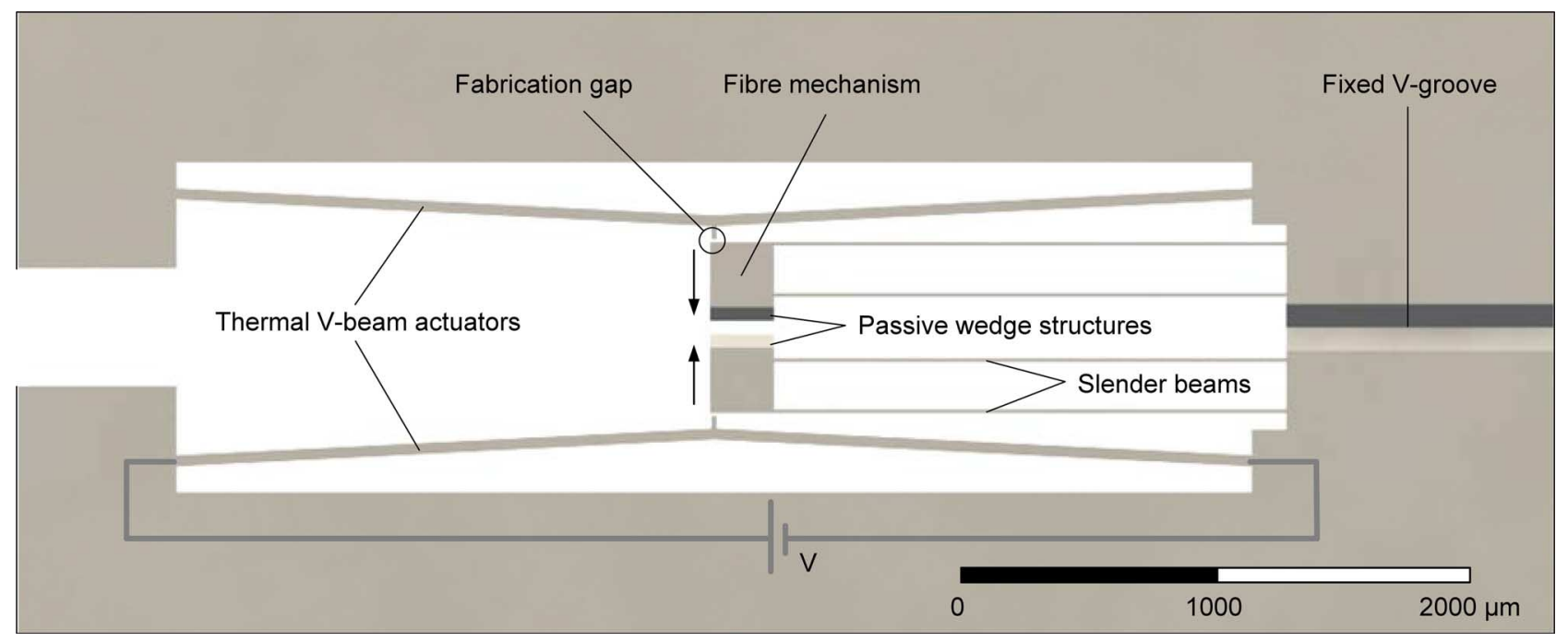

Fig. 2. Top view of the 2-DOF positioning device.

performed. Other solutions require specialized fiber preparation such as attaching permanent magnets to the fiber end [5], gold coating and grounding to enable actuation of the fiber [6], or expensive fabrication techniques, such as LIGA [7]. Another example is silicon wedge fabrication using gray-scale lithography [8], which is a rather new technology and is currently lacking surface smoothness due to the limited resolution of the lithography mask. The concept proposed in this research uses wedges formed by the $\langle 111\rangle$ planes in a silicon wafer, which is manufactured using a wet etching process. With these wedges it is possible to convert an in-plane actuator motion to both an in-plane and out-of-plane fiber motion, as illustrated in Fig. 1.

After positioning, the fiber mechanism can be clamped, thereby maintaining the fiber position without any power consumption. In case of misalignments due to disturbances, the clamp can be released and the fiber can be repositioned. The clamp can then be engaged again within a short amount of time.

In this paper, the design, modeling, fabrication, and experimental results of these devices are presented. Section II presents the design and working principle of the positioning device and clamping structure. Details of fabrication and fiberto-fiber alignment measurements are given in Sections III and IV, respectively. Section V presents the electrical, thermal and mechanical modeling of both devices, after which their performance and possible improvements are discussed in Section VI. Final conclusions can be found in Section VII.

\section{DeSIGN}

The two functionalities, positioning and clamping, both use thermal actuators. However, due to different configurations and design constraints, each function is treated here separately.

\section{A. Positioning Device}

Standard fiber-coupled laser diode packages for telecommunication applications use a fiber with a diameter of $125 \mu \mathrm{m}$ and a core of $8 \mu \mathrm{m}$. The fiber must be positioned in front of a laser

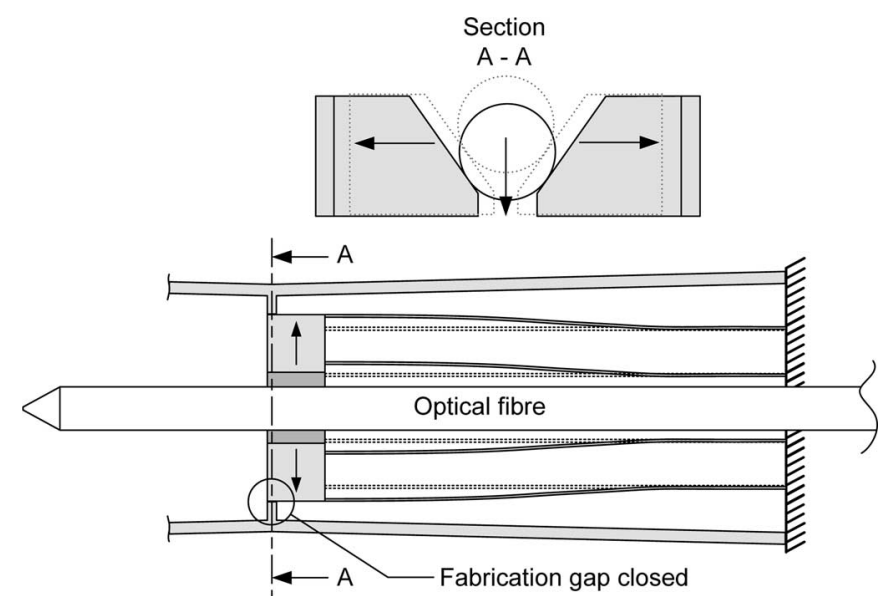

Fig. 3. Sideways motion of passive wedge structures due to fiber loading (sizes and deformations not to scale).

diode (typical beam output waveguide of $2 \times 0.4 \mu \mathrm{m}$ ) with a positioning accuracy on the order of $0.1 \mu \mathrm{m}$.

The top view of the actuator is shown in Fig. 2. The basic design consists of two thermal V-beam actuators with a length of $4200 \mu \mathrm{m}$, thickness of $45 \mu \mathrm{m}$ and an initial angle of $0.03 \mathrm{rad}$. They are used to position two fiber mechanisms on which a wedge is created by combining a wet and dry etching process. The slender beams of the fiber mechanisms are $2000 \mu \mathrm{m}$ long and $25 \mu \mathrm{m}$ wide.

A fixed $\mathrm{V}$-groove is manufactured on the wafer substrate and is located on a lower level in the wafer than the free V-groove on the fiber mechanisms. When the fiber is placed into the fixed V-groove, it causes a pretension force onto the fiber mechanisms. The two mechanisms are pushed against the thermal actuators, closing a $10 \mu \mathrm{m}$ wide fabrication gap (see Fig. 3).

Once the fiber is pressed onto the mechanisms, the positioning can then take place. The window in which the fiber can be positioned is diamond shaped, as shown in Fig. 4. By independently controlling the voltage level on the thermal actuators, lateral and vertical motions in the plane orthogonal to the fiber axis can be performed. 


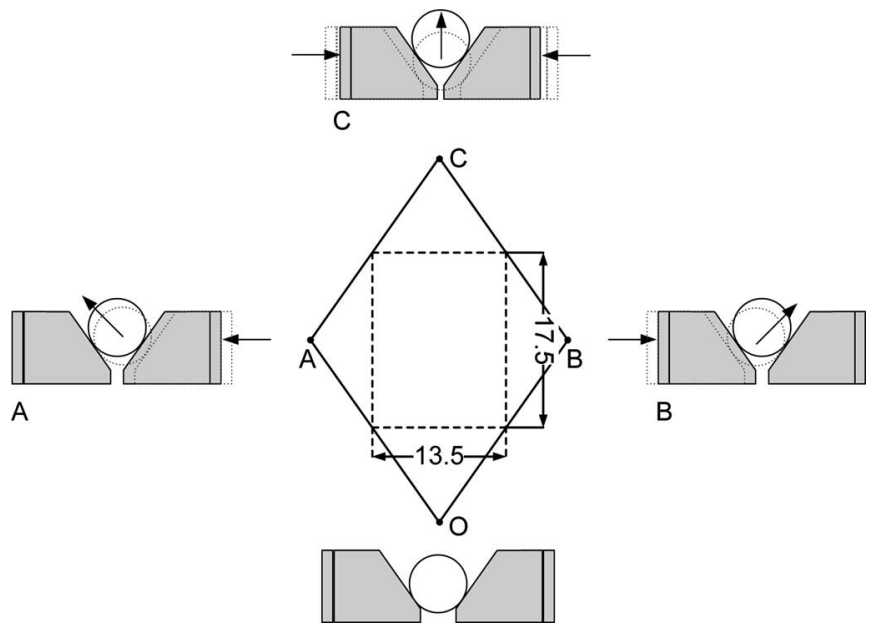

Fig. 4. Schematic representation of the diamond-shaped positioning window with the three outer actuation positions $\mathrm{A}-\mathrm{C}$ (dimensions in micrometers, positioning window not to scale).

The fine assembly process performed by the positioning device should be able to compensate for the tolerance error resulting from the coarse assembly process. The tolerance build up of the coarse assembly process requires a positioning rectangle circumscribed by the diamond shape of $13.5 \mu \mathrm{m}$ wide and $17.5 \mu \mathrm{m}$ high, as determined earlier [9]. Consequently, the size of the enclosing diamond shape based on the angle of the $\langle 111\rangle$ plane with the horizontal plane of $54.73^{\circ}$ is $27 \mu \mathrm{m}$ wide and $39 \mu \mathrm{m}$ high. Therefore, a single actuator should be able to move approximately $27 \mu \mathrm{m}$ and deliver sufficient force to position the fiber. In this case, a force of approximately $10 \mathrm{mN}$ is required based on calculations made on a bent fiber and on assuming a worst case friction coefficient between the mechanism and fiber of 0.4 [10]. Using this concept, a maximum parasitic fiber bending is approximately $1^{\circ}$, which is acceptable since it introduces negligible additional coupling loss.

\section{B. Clamping Device}

The second function of the device is maintaining the position of the fiber at any desired location within the positioning window, preferably without power. Although multiple-wafer solutions are principally possible, a single wafer configuration is preferred as no additional assembly steps are required to insert the mechanical clamp into the final device. To clamp without power, a separate locking mechanism can be used [11]. Alternatively, a prestressed structure, for instance, a bistable mechanism [12], thermally curable polyimide [13], or a rackand-tooth mechanism [14] must be created in the wafer.

The design presented here uses the movement of the fiber mechanism caused by the pretension force of the loaded fiber, as shown in Fig. 3, to initiate a novel clamping sequence. This movement, in combination with a friction-based rack-and-tooth mechanism, enables clamping of the fiber mechanism at any position within the positioning window.

Clamping the fiber mechanism can be described in the following four steps, as shown in Fig. 5. In the position after fabrication, the tooth of the clamp cannot move beyond the rack. When the fiber is loaded, the fiber mechanism moves aside

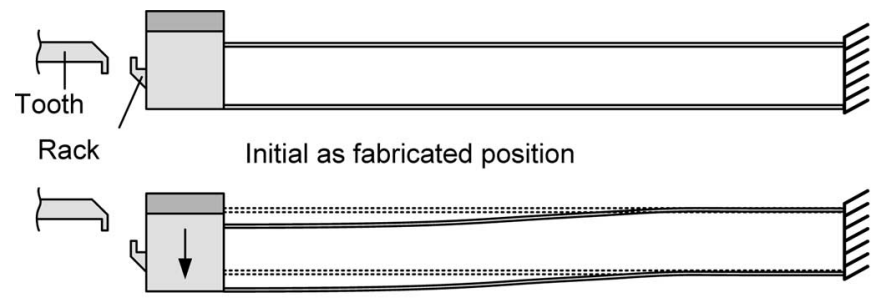

(1) Motion due to fibre loading

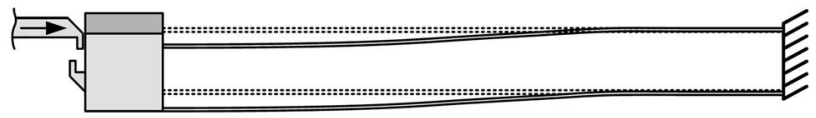

(2) Actuating the tooth

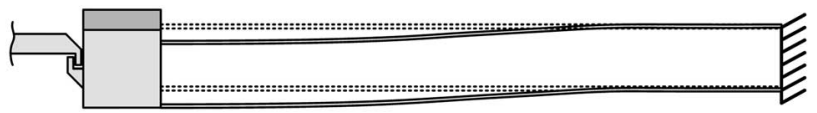

(3) Actuation of positioning device

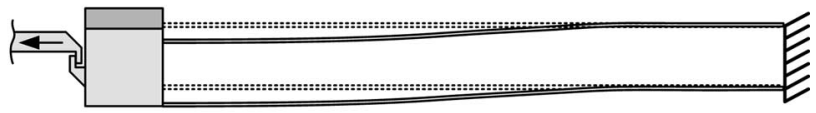

(4) Engage rack-and-tooth

Fig. 5. Four-step clamping sequence using the fiber loading to allow the tooth to pass the rack and enable unpowered clamping inside the positioning window.

(1) and the clamp is actuated until the tooth passes the rack of the fiber mechanism (2). The positioning actuator then moves the fiber to the desired position (3) and the mechanical clamp is then powered down, thereby engaging the clamp (4).

Using this particular device, only in-plane fiber movements are possible. Fig. 6 presents one side of the total positioning device on which the clamping structure, positioning actuator, and fiber mechanism can be recognized as all in-plane moving structures. For the actual device, this can be mirrored allowing for 2 DOF motions. Fig. 7 presents a zoomed image of the final design of the tooth of the mechanical clamp and the rack in the fiber mechanism.

The positioning stage uses a $4000 \mu \mathrm{m}$ long and $50 \mu \mathrm{m}$ wide V-beam actuator which is connected to a lever on a flexure hinge reversing the movement of the actuator. The mechanical clamp consists of an angled lever to enlarge the actuator stroke by a factor of two and is connected to a triple V-beam stack for large clamping stiffness. Cooling fins were included between the lever and the actuator. They limit the heat flow toward the lever tip, which causes expansion of the lever during actuation and shrinking while powering down. This thermal expansion is undesirable because this would result in a dynamic tip displacement and therefore, a final fiber alignment error.

The overall dimensions for the double-sided positioning device, including mechanical clamps, are approximately $5 \mathrm{~mm}$ by $6 \mathrm{~mm}$, which can fit easily into a standard optical fiber package.

\section{FABRICATION}

The first process run was performed to manufacture the two wedges and the simple actuators. A second process run was 


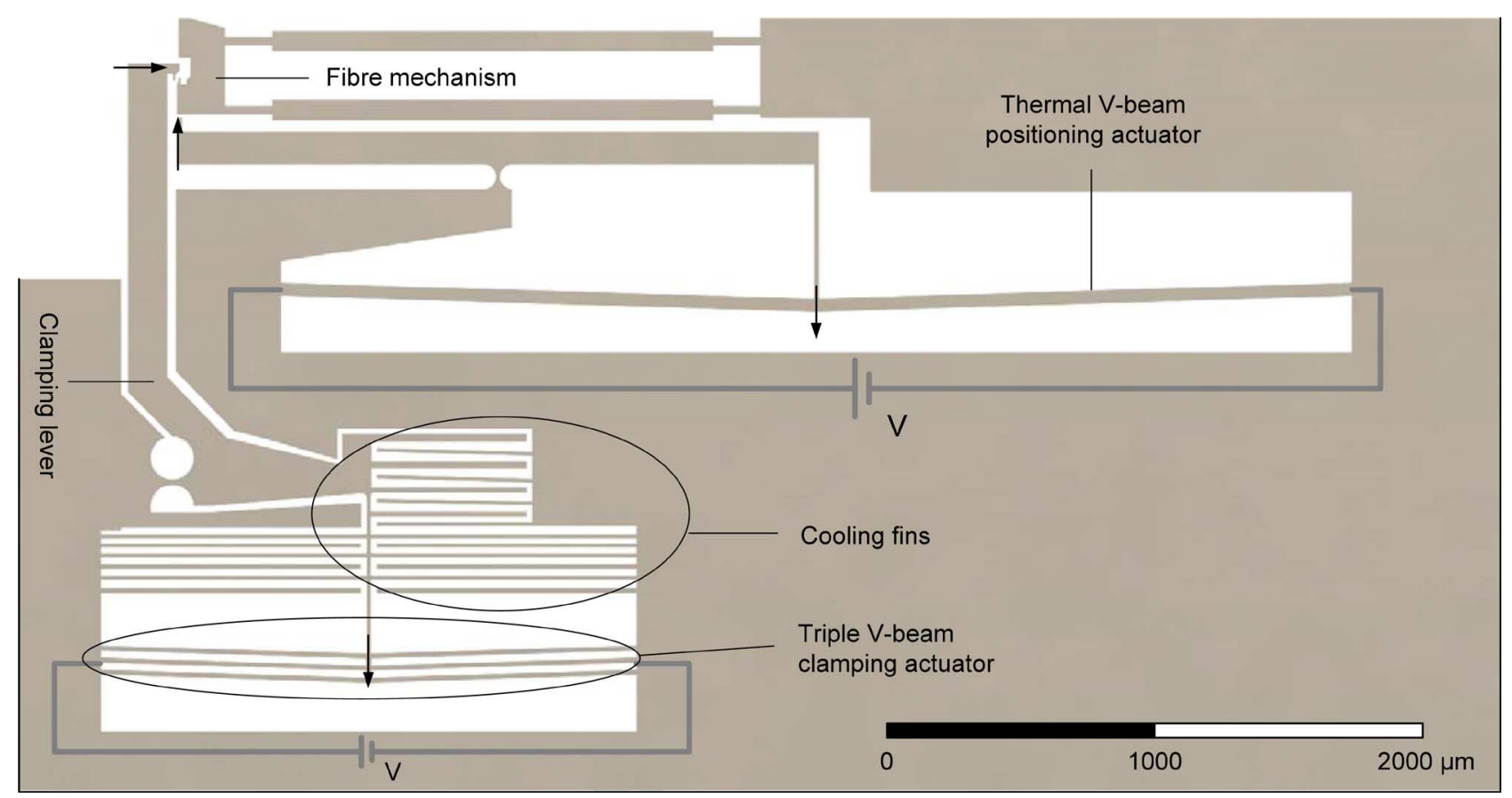

Fig. 6. Top view of the single side positioning and clamping concept.

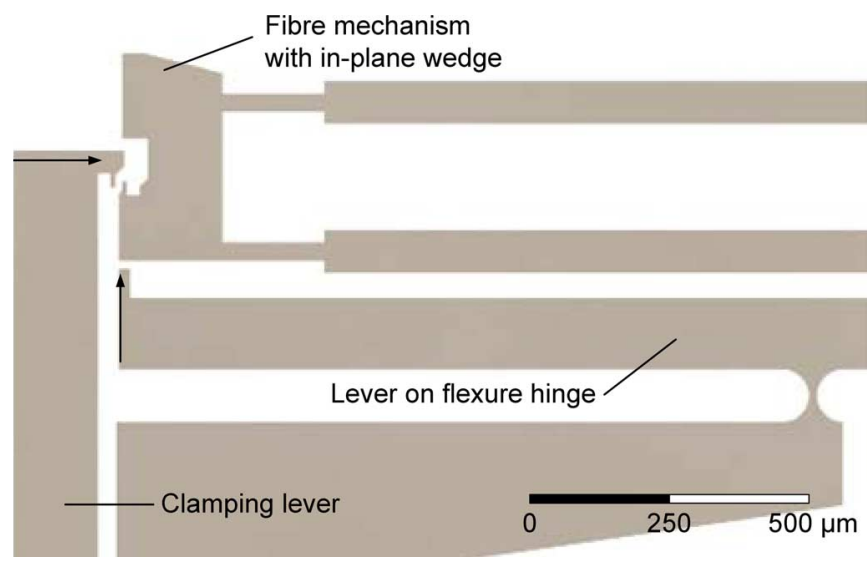

Fig. 7. Close up image of the fiber mechanism and clamp with in-plane wedge.

performed to assess the functionality of the mechanical clamp separately from the out-of-plane positioning device.

\section{A. Positioning Devices}

The positioning and clamping of the mechanisms and optical fiber requires large forces and a robust design of the structures. For this reason, the structures are manufactured in a standard $525-\mu \mathrm{m}$-thick silicon wafer. In this wafer a $150-\mu \mathrm{m}$-thick membrane is created by anisotropic etching of silicon in a $\mathrm{KOH}$ solution from the backside of the wafer. In this membrane, the structures are then etched by deep reactive ion etching (DRIE) from the front side.

Heating of the thermal actuators in the device takes place by current flow through a thin polysilicon layer on top of the bulk material. The V-grooves on the front side of the wafer are also created using anisotropic wet etching in $\mathrm{KOH}$.
A schematic overview of the process sequence used to fabricate the devices is presented in Fig. 8. On the substrate, a 300 -nm-thick oxide layer is thermally grown, followed by a 300-nm-thick low stress SiN layer deposited by LPCVD (1). On top of this layer, a 500-nm-thick low stress polysilicon layer is deposited by LPCVD. This layer is doped with phosphorous in a diffusion process and patterned using a resist mask and a dry etching step (2).

Next, the V-grooves are created in the front side of the wafer (3). A second layer of $\mathrm{SiN}$ is deposited and patterned. The silicon is etched in a $33 \mathrm{wt} \% \mathrm{KOH}$ solution to form the $100-\mu \mathrm{m}$-deep V-grooves. At this point, the contact openings to the polysilicon and the Al metallization are realized. For these two lithography steps, the resist is spray coated to uniformly cover the planar surface as well as the V-grooves side walls and bottom.

Then, the membranes are defined on the backside of the wafer (6) as well as the DRIE structures on the front side of the wafer (7). For the masking layer in the DRIE process, a 3.0- $\mu \mathrm{m}$-thick PECVD oxide layer was used. At this point, the wafer presents a high topography surface and the fine structures need to be patterned at different depths. To achieve this, a newly developed spray coater, EVG 101, at the EV Group in Austria is used. Moreover, the structures are divided in two DRIE masks. The first mask contains only the DRIE openings inside the $\mathrm{KOH}$ cavities. Extra time is necessary to expose the resist in the deep cavities. This extra exposure time would alter the dimensions of the small structures present on the planar part of the wafer. A second DRIE mask that contains all DRIE structures is then applied.

Before the dry etching step, the membranes are etched from the backside using a $\mathrm{KOH}$ etching process until a $150-\mu \mathrm{m}$ thick silicon membrane remains (8). A 500-nm aluminum stop layer for the DRIE process is then deposited on the backside of 


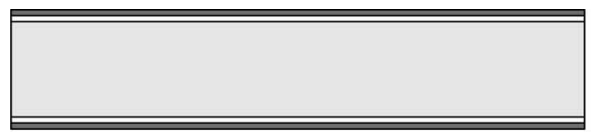

1. Thermal oxidation and $\mathrm{SiN}$ deposition

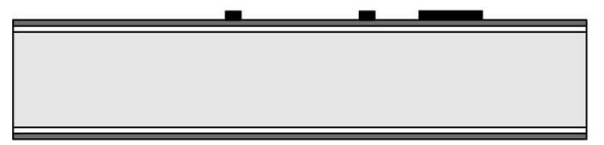

2. Etching polysilicon elements

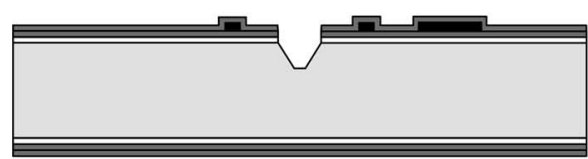

3. $\mathrm{KOH}$ etching front side

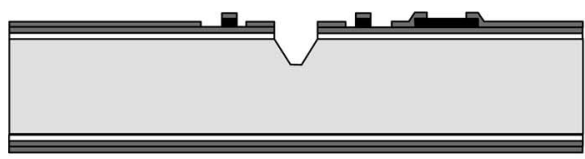

4. Dry etching contact openings

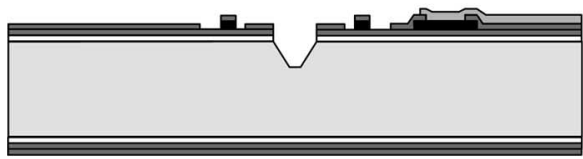

5. Dry etching Al interconnects

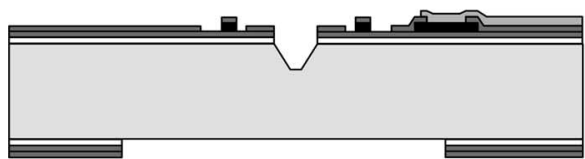

6. $\mathrm{KOH}$ definition backside

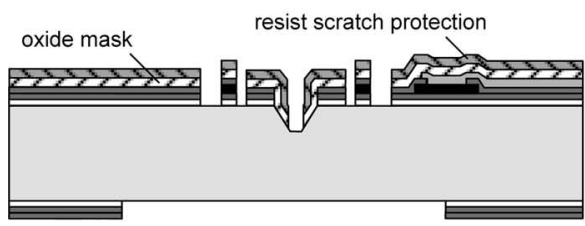

7. DRIE definition front side

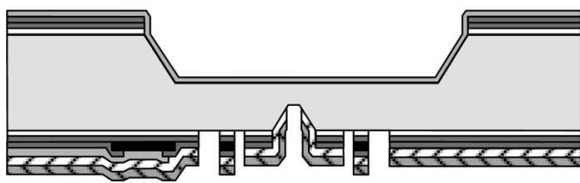

8. Backside $\mathrm{KOH}$ etching
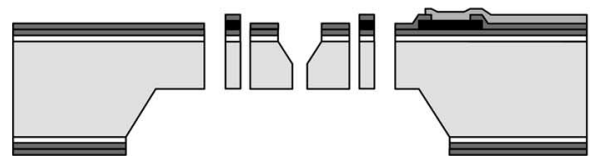

\section{Silicon DRIE}

Fig. 8. Fabrication sequence of the process run including in-plane actuation structures and $\mathrm{KOH}$-etched $\langle 111\rangle$ planes for fiber tip out-of-plane motion conversion.

the wafer. In the final step, the scratch protection is removed and the DRIE step is executed. Finally, the aluminum stop layer on the backside and the oxide layer on the front side are removed (9). After dicing and wire bonding, the devices are ready to be tested.

The integration of the wet etching process with the partially overlapping dry etching process to realize the movable fiber wedges introduced some complexities. After the DRIE step, a thin silicon frame is left at the edges in place of the front side $\mathrm{KOH}$ mask (see Fig. 9). This is probably due to a small underetch during the $\mathrm{KOH}$ step that causes an unintentional protection of the edge of the pattern during the DRIE process.
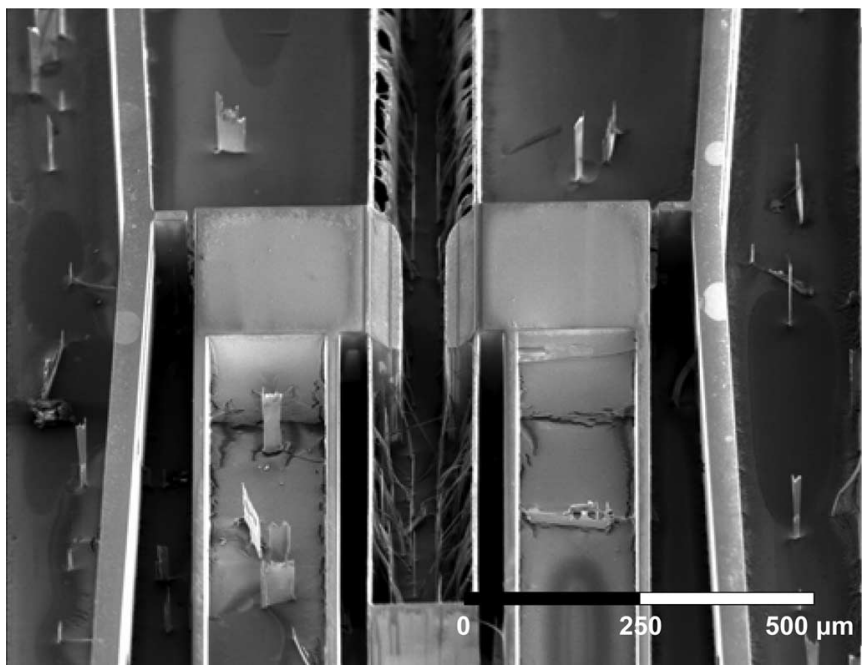

Fig. 9. SEM detailed image $\left(45^{\circ}\right.$ tilt $)$ of fiber mechanisms before the backside processing. The remaining vertical frame is clearly visible.

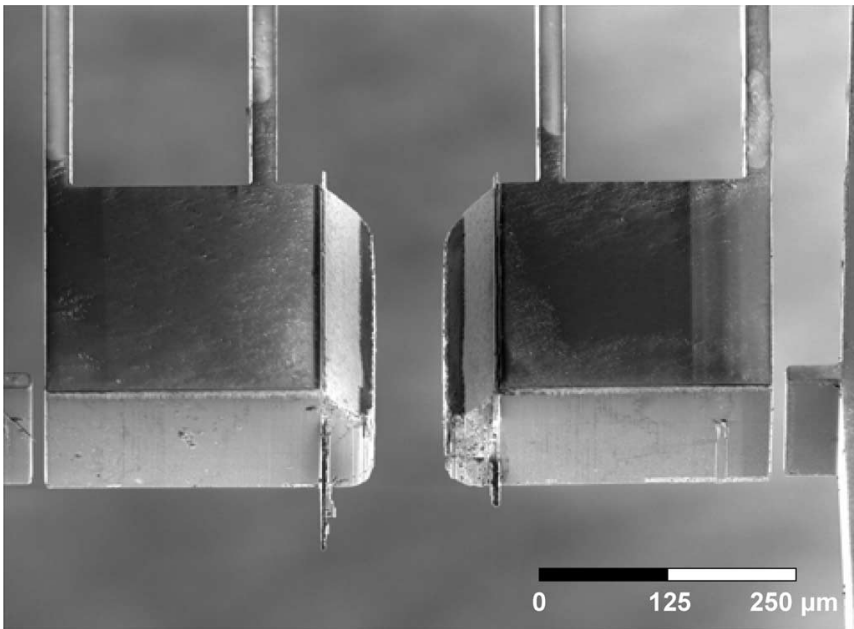

Fig. 10. SEM close up of $\langle 111\rangle$ plane wedges after full release and with frame removed.

This frame is mechanically removed from the devices resulting in the fully released structures presented in Fig. 10. With some minor adaptations of the $\mathrm{KOH}$ etching process and a modification of the layout, the underetch can be reduced and this problem can be avoided in future fabrication.

The surfaces of the movable wedges are very smooth in appearance. The darker areas at the bottom of the wedges indicate some aluminum residues. This is only a very thin layer on the $\langle 111\rangle$ plane and it does not have a noticeable influence on the fiber positioning.

\section{B. Clamping Devices}

Fabrication of the second process run included the mechanical clamping concepts without the wedges on the fiber mechanisms was performed nearly the same as the first process. The main difference is that the third step, $\mathrm{KOH}$ patterning and etching on the front side, does not take place. The fabricated devices from the second process run and a close-up image of the clamp itself are shown in Figs. 11 and 12, respectively. 


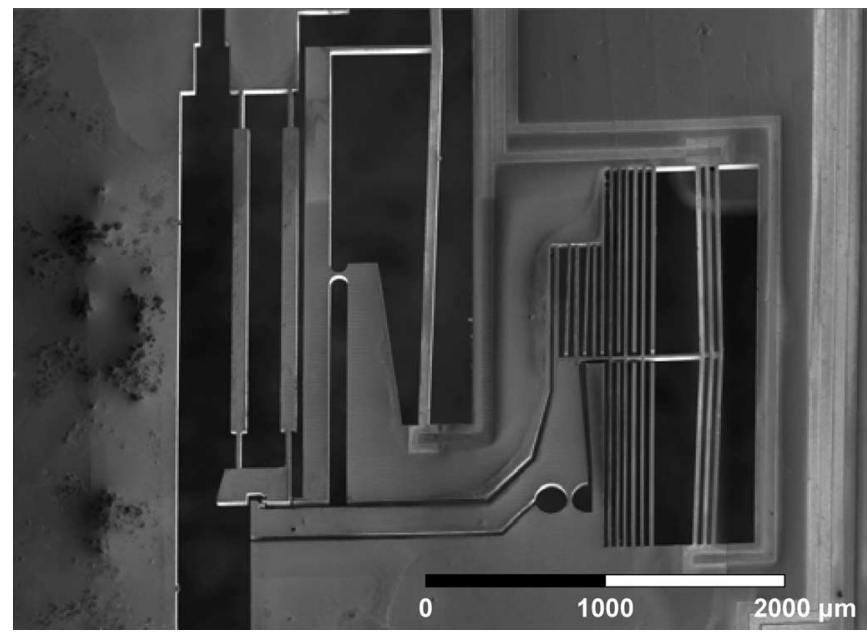

Fig. 11. Fabricated mechanical clamp and positioning device.

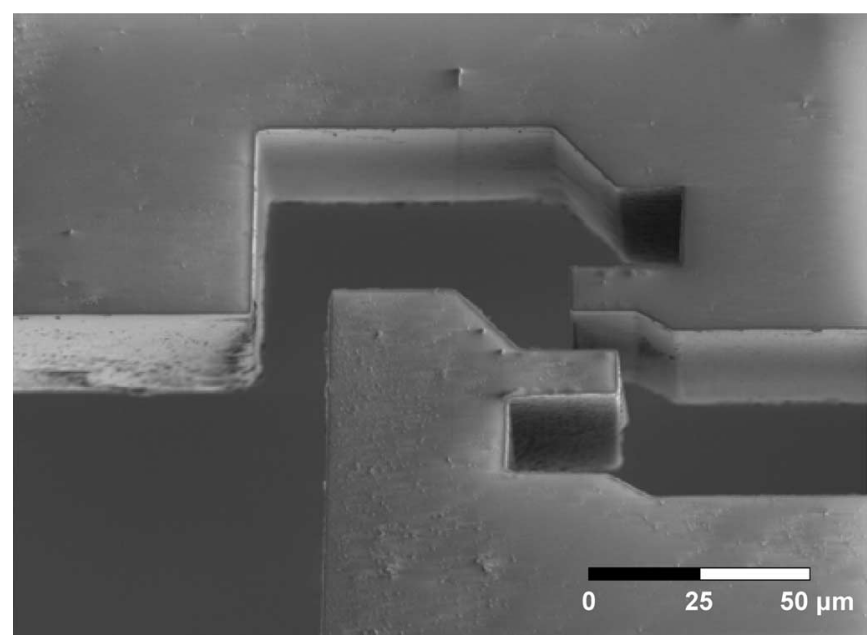

Fig. 12. Close up of the rack-and-tooth mechanism.

\section{Measurements}

The functionality is intended for fiber-to-laser alignment. However, in these experiments, a fiber-to-fiber arrangement was used for convenience. Similarly, single mode fiber with a core of $4.3 \mu \mathrm{m}$ was used because visible red light with a wavelength of $635 \mathrm{~nm}$ was easier to handle during the experiments than standard telecommunication fiber having a core of $8 \mu \mathrm{m}$ to be operated at a wavelength of $1550 \mathrm{~nm}$.

\section{A. Positioning Functionality}

The size of the actual positioning window was measured using a fiber-to-fiber alignment test setup, of which a schematic is shown in Fig. 13. In this setup, two fiber ends are placed opposite to each other and light was coupled from one fiber to the other, continuously measuring the coupled power. One fiber was placed on the actuator chip and the other on a computercontrolled XYZ-actuation stage. By alternatively moving the fiber on the actuator chip and positioning the actuation stage until the maximum coupled power was regained, it was possible to calculate the fiber tip movement as a function of actuation voltage. Using this procedure, the size of the po- sitioning window of the device was determined. The same program was used to determine the possible resolution of the devices, the clamping stability, and the displacement of the fiber end when the mechanical clamp and positioning device were powered down.

During the measurements, different fiber overhang lengths were used when measuring the size of the positioning window of the device. The overhang length is defined as the amount of fiber extending beyond the end of the fiber mechanism. Increasing the overhang length significantly enlarges the size of the positioning window because of the angular pivot with the fixed V-groove. The positioning window measurements are presented in Fig. 14(a) and (b). These measurements were performed with approximately $1000-\mu \mathrm{m}$ fiber overhang.

The results in Fig. 14(a) show, as expected, a diamondshaped window in which the fiber tip can be positioned. The positioning window is slightly tilted by $1.5^{\circ}$, which can be attributed to a rotational error along the axis of the fiber in the experimental setup. The left and right lines each show two separate actuator movement sequences. An increasing voltage across the right actuator (see Fig. 4) results in a displacement from $\mathrm{O}$ to $\mathrm{A}$ in Fig. 14(a). Then, holding the right actuator at a constant voltage and applying an increasing voltage across the left actuator results in a displacement from $\mathrm{A}$ to $\mathrm{C}$. This completed the trace of the left side boundary of the diamondshaped positioning window from the bottom vertex $(\mathrm{O})$ to the top vertex $(\mathrm{C})$. By moving both actuators sequentially after each other, the final position of the fiber was approximately $43 \mu \mathrm{m}$ vertically above the starting position. The right side boundary was obtained by resetting the actuators to $0 \mathrm{~V}$ and then reversing the actuator order. This resulted in the traces from $\mathrm{O}$ to $\mathrm{B}$, and then, from $\mathrm{B}$ to $\mathrm{C}$. The middle line in Fig. 14(a) shows the fiber motion when an equal voltage is applied to both actuators at the same time. All three lines ended at the same nominal position. The maximum applied voltage to each separate actuator was $36.5 \mathrm{~V}$, which resulted in a $27-\mu \mathrm{m}$ wide and $43-\mu \mathrm{m}$-high positioning window with sides having directions in agreement with the etched $\langle 111\rangle$ planes.

The friction between the fiber end and the $\langle 111\rangle$ plane will cause hysteresis and a stick-slip effect. A hysteresis measurement was performed which is presented in Fig. 14(b). The first sequence consisted of an upward motion of the fiber with an increasing voltage applied first to the right actuator and then to the left actuator. In the second sequence, the actuator voltages are decreased in reverse order. The results indicate that the hysteresis has a minimal effect in positioning the fiber tip with this device.

To measure the effects of stick-slip, the left actuator was held constant at a voltage of $33.5 \mathrm{~V}$ and the right actuator was displaced from 33.5 to $36.5 \mathrm{~V}$ using a linear step of $50 \mathrm{mV}$, which was the minimal stable voltage output of the test setup. At these high voltages, the output sensitivity of the actuator was the highest, resulting in the worst attainable displacement resolution. Fig. 15 shows the measured $x-y$ displacement plot with the same $1000-\mu \mathrm{m}$ fiber overhang, and because there are no large jumps between successive data points, it is assumed that the stick-slip has little effect on the displacement of the actuator. The $x$-direction is also the direction of actuation, therefore, 


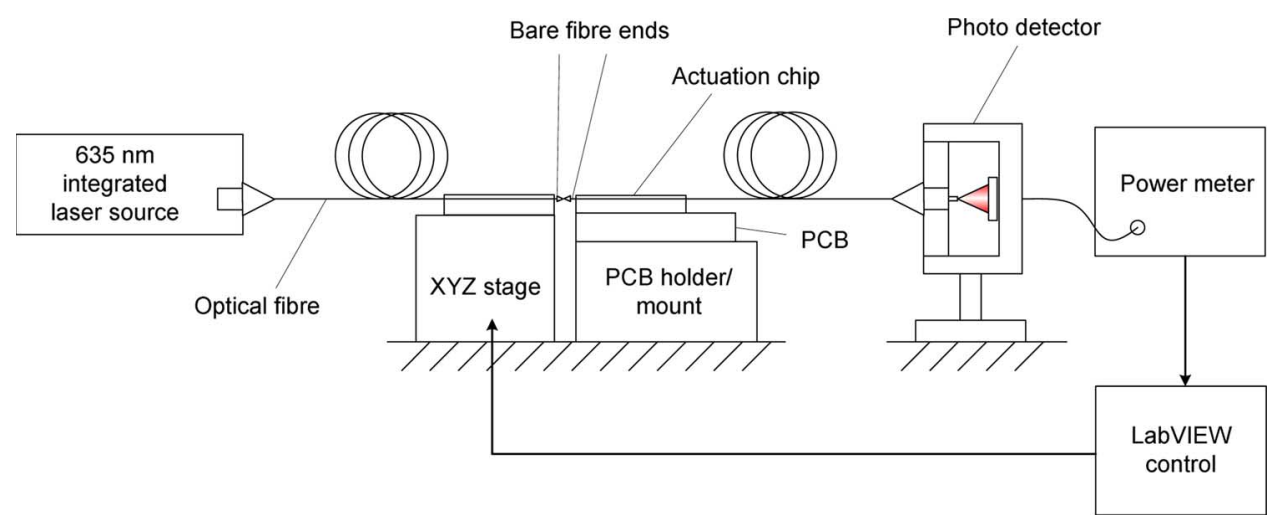

Fig. 13. Schematic representation of the fiber-to-fiber alignment test setup.

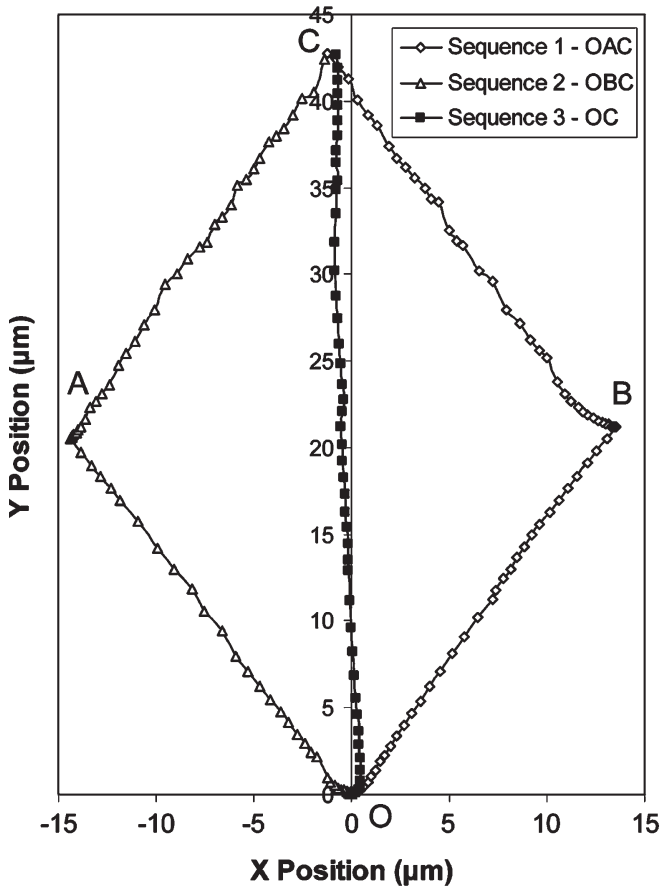

(a)

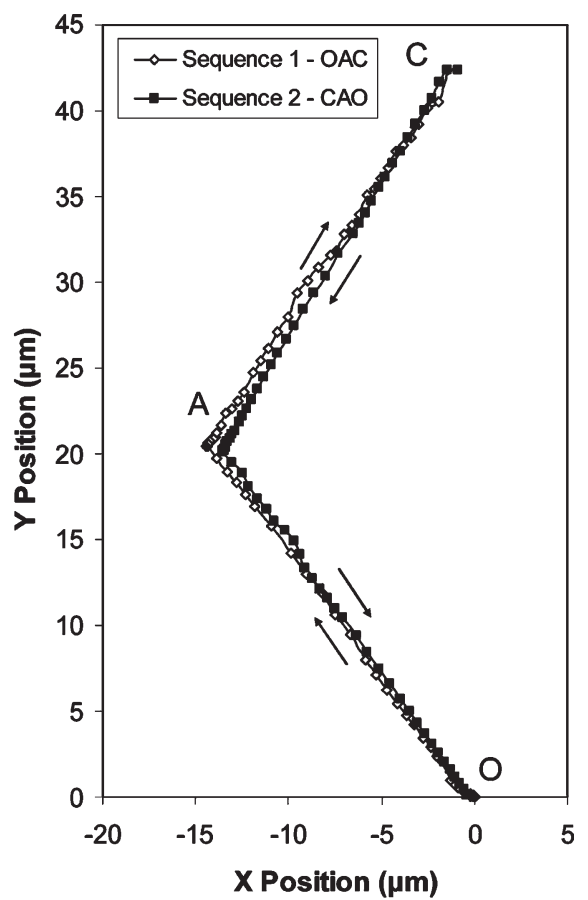

(b)

Fig. 14. Positioning measurements with 1000- $\mu \mathrm{m}$ fiber overhang: (a) measured 2-D positioning window; (b) upward and downward fiber motion to show hysteresis due to friction between fiber and $\langle 111\rangle$ plane wedges.

this was used as the reference direction in the measurement to determine the linearity of the $y$ data. For comparison, the silicon $\langle 111\rangle$ lattice plane, which would be an ideal datum, has a slope of 1.41 (the square root of 2). The measured slope of $y$ with respect to $x$ was 1.32. Although there is a difference between the ideal slope and the measured value, this can be attributed to rotational misalignment shown in Fig. 14(a) and not to stick-slip.

Using a linear least squares approximation, the difference from this and the measured value was less than $\pm 0.1 \mu \mathrm{m}$. However, the difference appeared to have a nonlinear component in the signal. Because the data does not show significant effects of stick-slip, the source of this nonlinearity may be due to the nonlinear displacement characteristics of the actuator. An example of the nonlinearity in the actuator is shown in Fig. 16, however, the difference from ideal and the stick-slip effects were less than the target values and this was not investigated further.

\section{B. Clamping Functionality}

The positioning device fabricated together with the clamping mechanism is only capable of in-plane fiber positioning because the passive wedges were not manufactured. The positioning range is shown in Fig. 16. The displacement is measured for both a 10- and 1000- $\mu \mathrm{m}$ overhang. Based on these results, there is a significant difference between the fiber displacement with a small amount of overhang and with a large fiber overhang.

The measured actuation stroke is $26 \mu \mathrm{m}$ at $33 \mathrm{~V}$, just below the required positioning range of $27 \mu \mathrm{m}$, which can be reached by slightly increasing the actuator voltage. The thermal 


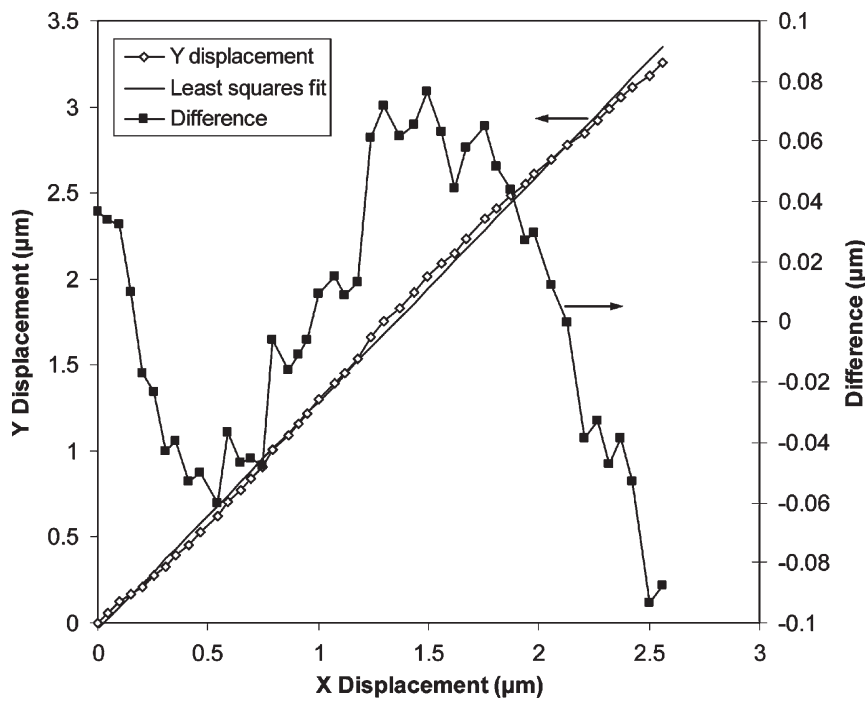

Fig. 15. $x-y$ displacement upon actuator voltage steps of $50 \mathrm{mV}$ from 33.5 to $36.5 \mathrm{~V}$.

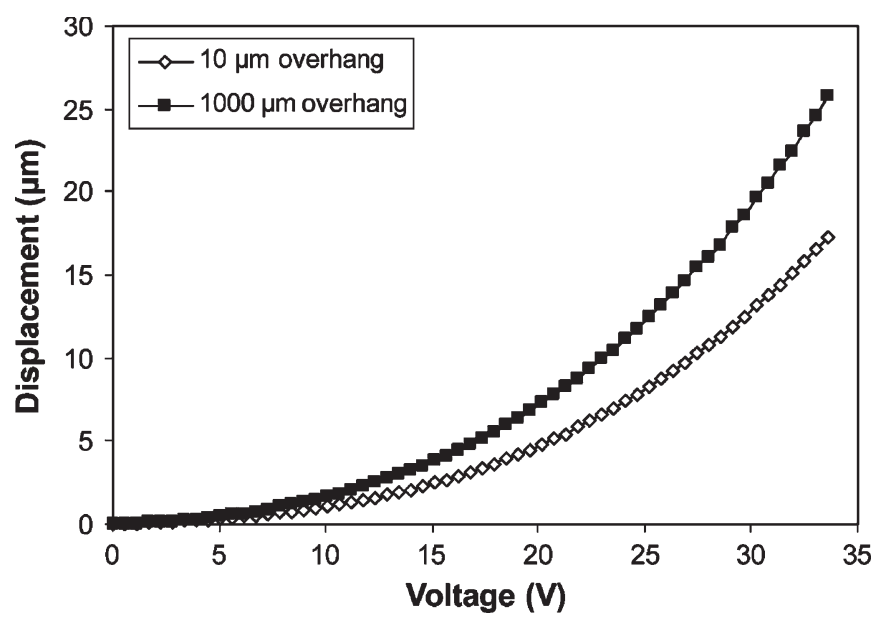

Fig. 16. Measured in-plane fiber displacement with $10-$ and $1000-\mu \mathrm{m}$ fiber overhangs.

modeling, presented in the next section, showed that this can be safely done without overheating the structure.

The clamping sequence is shown in Fig. 17(a)-(d). Fig. 17(a) shows the fiber mechanism being pushed against the positioning actuator by the inserted fiber. A voltage was then applied to the clamping actuator to allow the tooth of the clamping lever to pass the rack of the fiber mechanism (b). Next, the fiber was aligned with respect to the opposing fiber end (c) and the actual clamping was started. First, the clamp actuator was shut off, after which the positioning actuator was powered down, leaving the device completely without power (d). As shown in Fig. 17(d), the fiber remains aligned with the second fiber, even when both the positioning actuator and clamping actuator are switched off.

The position shift during clamping was tested at different positions of the fiber. After fine positioning of the fiber, the clamping sequence (powering down both clamp and positioning device) was performed and the fiber displacement was measured. From repeated measurements it was determined that the

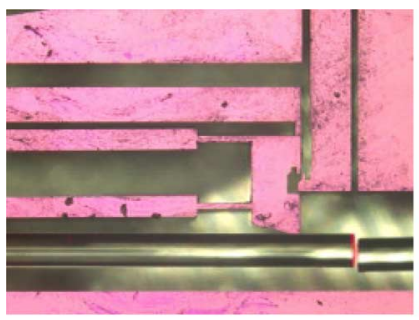

(a)

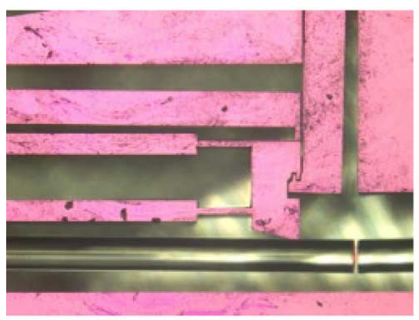

(c)

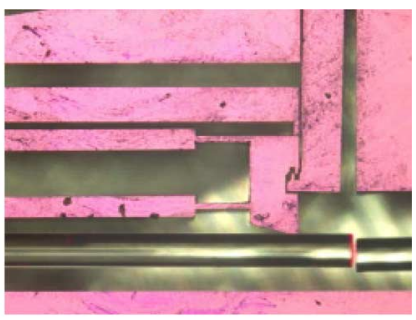

(b)

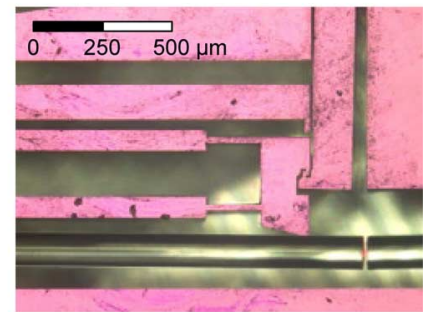

(d)
Fig. 17. Fiber positioning and clamping sequence: (a) position without power including inserted fiber; (b) actuation of the clamp; (c) moving the fiber to the desired position; (d) engaging the clamp by powering down the voltage followed by powering down the positioning actuator. The fiber remains aligned without power.

clamping displacement at all tested positions is less than $0.1 \mu \mathrm{m}$ and therefore, meets the fiber-to-laser coupling requirements.

The devices were also tested for their resistance against vibrations, from 0 to $2000 \mathrm{~Hz}$ up to $15 \mathrm{~g}$. The lowest resonance frequencies of the structures are much higher than $2000 \mathrm{~Hz}$ ( $7 \mathrm{kHz}$ for the fiber mechanism, $27.9 \mathrm{kHz}$ for the positioning actuator, and $25.8 \mathrm{kHz}$ for the clamping structure), and therefore little damage, if any, to the structure is expected. Both the clamped device and the unclamped device have been tested in three orthogonal directions. No visible failure or shift in clamping position was observed after the experiments indicating that the device will perform well under working conditions.

\section{THERMAL MOdELING}

The electrical, thermal, and mechanical behavior and their coupling was modeled using Comsol Multiphysics finiteelement (FE) modeling software. To investigate the temperatures in the actuators the FE model was adjusted to match the fabrication parameters. The temperatures in the actuators must remain below the recrystallization temperature $(870 \mathrm{~K})$ of polycrystalline silicon to prevent thermal runaway [15], [16] and consequently, permanent changes in the behavior of the actuators. The model was further simplified by using only 2-D geometries to significantly decrease calculation time. Also, the thin polysilicon resistor layer was not modeled separately. Instead, an equivalent electrical resistivity for the bulk silicon was calculated, which was considered admissible since the Biot number for the cross section of the structures is fairly small [17]. This indicates that the required time for the heat to penetrate from the top of the cross section to the bottom is short compared to the time required to transport the heat to the anchors. 


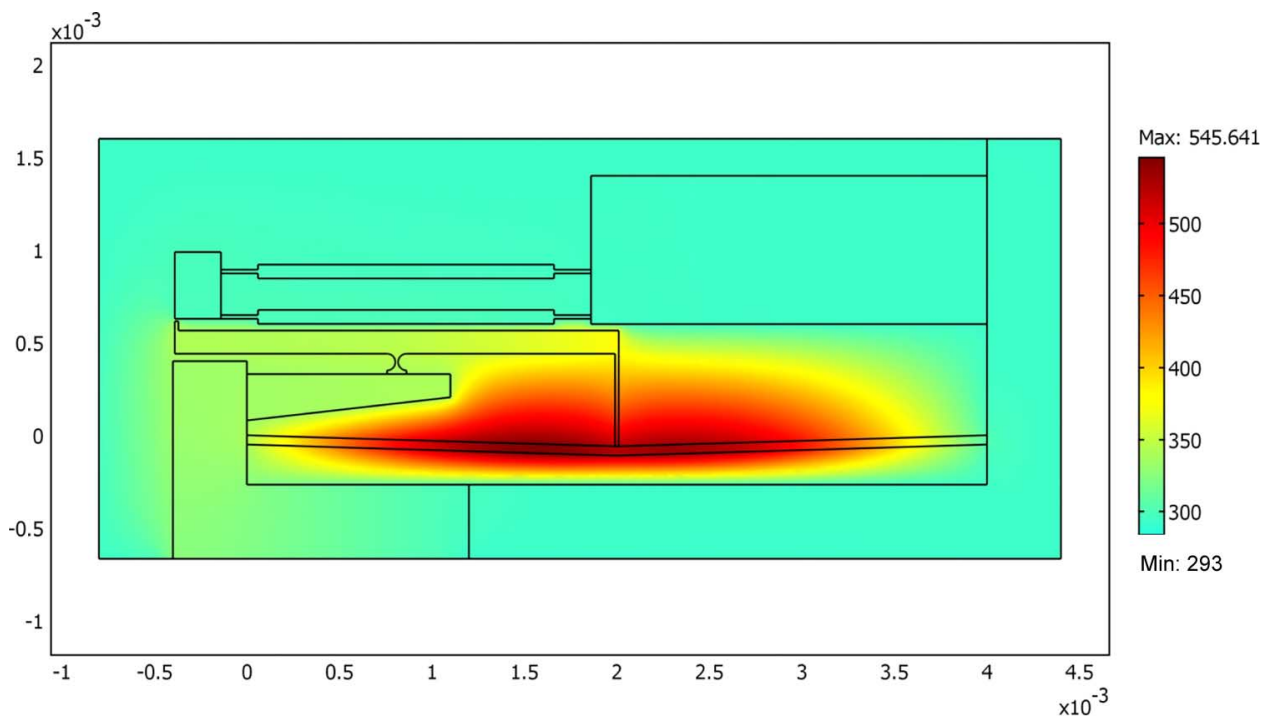

Fig. 18. Temperature plot of modeled positioning structure at $35 \mathrm{~V}$ (in kelvin).

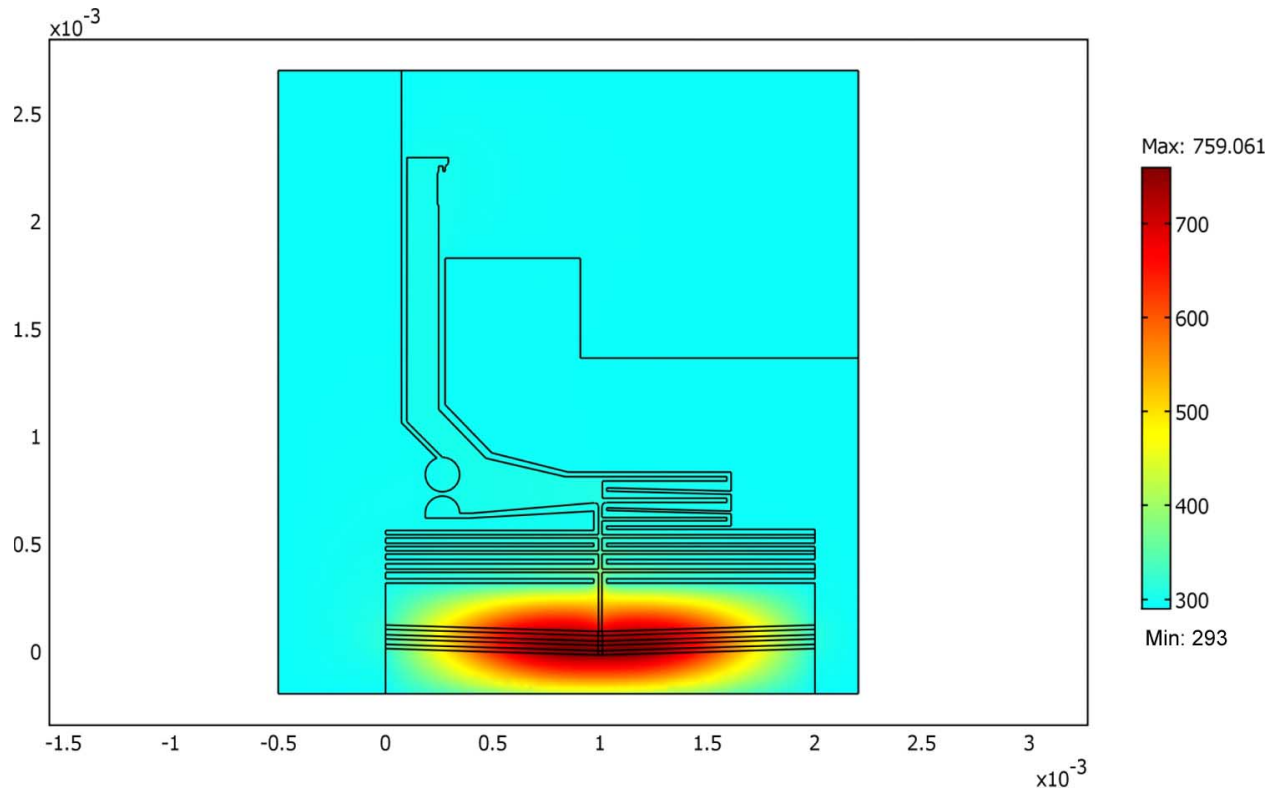

Fig. 19. Temperature plot of modeled clamping structure at $41 \mathrm{~V}$ (in kelvin).

The electrical resistivity is strongly dependent on temperature and differs depending on the doping type and level. With a phosphorous doping concentration of approximately $10^{20}$ atoms $/ \mathrm{cm}^{3}$ in the polysilicon resistor layer, the equivalent electrical resistivity over the bulk silicon cross section was calculated to be $3.0 \times 10^{-3} \Omega \cdot \mathrm{m}$ at room temperature. A linear expression for the electrical resistivity as a function of temperature was used to fit the modeled resistance to the measured values, which was determined to be adequate for these simulations. The thermal conductivity and the thermal expansion coefficient of single crystal silicon are also strongly temperature dependent and their values were taken from Lide [18] and Okada and Tokomaru [19], respectively.

In addition to heat conduction through the solid material, conductive and convective heat transfer through air and radiation were included. Temperature-dependent values of den- sity and thermal conductivity of air were taken from Mills [20], as well as formulas for the convection coefficient for macrosystems, which were extrapolated to the microdomain. For the radiation estimation, the structures were modeled as gray bodies with an emissivity of 0.7 [17], [21].

The resistivity and displacement curves are in agreement with the experimental data and therefore, the modeled temperatures are assumed to be correct. The modeled temperature of the positioning actuator at $35 \mathrm{~V}$ is shown in Fig. 18. To determine the displacement, a force was applied to the actuator tip equivalent to the force exerted on the fiber mechanism by the fiber. The maximum displacement of approximately $16.5 \mu \mathrm{m}$ is comparable to the experimental result with $10 \mu \mathrm{m}$ overhang presented in Fig. 16. This displacement was achieved at less than the maximum temperature, indicating that the actuator can be manufactured more compactly. 
The temperature level in the mechanical clamp was also investigated. The temperature profile at $41 \mathrm{~V}$ is shown in Fig. 19. From this simulation, there is only a very small heat flow into the lever due to the cooling fins. The clamp design was optimized such that the modeled vertical position shift upon cooling was zero. The required $35 \mu \mathrm{m}$ horizontal displacement for passing the rack is achieved at approximately $760 \mathrm{~K}$, which is below the allowable temperature of $870 \mathrm{~K}$.

\section{DISCUSSION}

The fabricated devices confirmed that the two individual functionalities, 2-DOF positioning using $\langle 111\rangle$ plane wedges and mechanical clamping without power, show that fiber alignment can be performed. Additional investigations should be performed on the combined functions to verify their joint performance. Problems such as thermal crosstalk are not expected based on the obtained modeling and test results. During the measurements, there was little, if any, crosstalk observed between the various components.

The positioning and clamping functionalities can probably be further optimized due to a decrease in tolerance build up from the coarse assembly process. Initially, it was assumed that the laser diode needed to be mounted on a separate substrate. When bonding is taken into account in the processing with the present design, it is most likely possible to place the laser diode directly on the actuation chip, thereby allowing for a smaller positioning window. Consequently, smaller actuator strokes and forces are allowed. This also means that the device can be made more compact, reducing the cost, which is strongly related to the surface area on the wafer.

To prevent the remaining frame shown in Fig. 9, the combination of wet and dry anisotropic etching needs to be optimized. This can be achieved by using conditions that minimize underetch and that are less sensitive to crystal orientation.

The device is able to position the fiber in 2 DOF. The preceding assembly steps should account for the remaining 4 DOF for which less demanding tolerances apply. Due to the pretension configuration, gluing of the fiber into the fixed groove is able to take care of the three rotational degrees of freedom. In the longitudinal direction, however, the fiber should be positioned with sufficient accuracy using external positioning equipment or manually, because constructing structures for aligning the fiber in this direction is not easily achieved. Integration of the coarse and fine assembly process is considered very important.

Measurements on the step response behavior of the thermal positioning actuator showed settling times of approximately $0.5 \mathrm{~s}$, which is fast enough for assembly purposes. The total optimization including constraining the final position can take place in a matter of seconds.

\section{CONCLUSION}

A 2-DOF fiber positioning device and clamping structure for the purpose of aligning a single mode optical fiber to a laser diode has been designed, modeled, fabricated, and tested in a fiber-to-fiber alignment arrangement. The results showed fiber tip displacements in a diamond-shaped positioning window of over $25 \mu \mathrm{m}$ in-plane and more than $40 \mu \mathrm{m}$ in the out-of-plane direction with only a small hysteresis effect visible. Positioning resolutions smaller than $0.1 \mu \mathrm{m}$ were measured and correcting for nonlinearity in the actuator may also lead to a significant improvement in displacement resolution. Powering down the clamping actuator and positioning actuator showed an average shift in position of less than $0.1 \mu \mathrm{m}$, and no visible shift in clamping position was observed after a series of vibration tests, therefore the final position was assumed to be stable. These initial results serve as a solid base for further improvement of the device performance with minor layout and fabrication modifications.

\section{ACKNOWLEDGMENT}

The authors would like to thank C. Thanner of EV Group Austria for spray coating the wafers and $\mathrm{H}$. van der Burgh for his contribution to the design of the mechanical clamping structure. The devices were manufactured at the Delft Institute of Microsystems and Nanoelectronics. This paper belongs to the Delft Centre for Mechatronics and Microsystems of the TU Delft.

\section{REFERENCES}

[1] P. Schwab, T. Bowen, R. Perko, N. Delen, J. Goodrich, and R. Anderson, "A high throughput optoelectronic module assembly process," in Proc. 54th Electron. Compon. Technol. Conf., 2004, vol. 2, pp. 1475-1478.

[2] A. Unamuno, J. Yao, and D. Uttamchandani, "Alignment and fixing of fiber optics based on electrothermal MEMS actuators," IEEE Photon. Technol. Lett., vol. 17, no. 4, pp. 816-818, Apr. 2005.

[3] R. R. A. Syms, H. Zou, J. Yao, D. Uttamchandani, and J. Stagg, "Scalable electrothermal MEMS actuator for optical fibre alignment," J. Micromech. Microeng., vol. 14, no. 12, pp. 1633-1639, Dec. 2004.

[4] S. Aoshima, N. Yoshiwaza, and T. Yabuta, "Compact mass axis alignment device with piezoelements for optical fibers," IEEE Photon. Technol. Lett., vol. 4, no. 5, pp. 462-464, May 1992.

[5] T. Frank, "Two-axis electrodynamic micropositioning devices," J. Micromech. Microeng., vol. 8, no. 2, pp. 114-118, Jun. 1998.

[6] M. Luetzelschwab, D. Weiland, and M. P. Y. Desmulliez, "Submicron alignment of a two-dimensional array of multiple single-mode fibers," IEEE Photon. Technol. Lett., vol. 17, no. 12, pp. 2634-2636, Dec. 2005.

[7] J. M. Haake, R. L. Wood, and V. R. Dhuler, "In-package active fiber optic micro-aligner," in Proc. SPIE—Int. Soc. Opt. Eng., 1998, vol. 3276, pp. 207-219.

[8] B. Morgan, J. McGee, and R. Ghodssi, "Automated two-axes optical fiber alignment using grayscale technology," J. Microelectromech. Syst., vol. 16, no. 1, pp. 102-110, Feb. 2007.

[9] V. A. Henneken and M. Tichem, "Tolerance budgeting in a novel coarsefine strategy for micro-assembly," in Proc. 3rd IPAS, Bad Hofgastein, Austria, Feb. 2006, pp. 155-166.

[10] K. Deng and W. H. Ko, "A study of static friction between silicon and silicon compounds," J. Micromech. Microeng., vol. 2, no. 1, pp. 14-20, Mar. 1992.

[11] J. D. Grade, K. Y. Yasumura, and H. Jerman, "Micromachined actuators with braking mechanisms," Sens. Actuators A, Phys., vol. 122, no. 1, pp. 1-8, Jul. 2005.

[12] J. Qui, J. H. Lang, and A. H. Slocum, "A curved-beam bistable mechanism," J. Microelectromech. Syst., vol. 13, no. 2, pp. 137-146, Apr. 2004.

[13] A. Baba, H. Okano, H. Uetsuka, and M. Esashi, "2 axis optical switch with holding mechanism," in Proc. 16th IEEE Conf. MEMS, Kyoto, Japan, Jan. 2003, pp. 251-254.

[14] R. R. A. Syms, H. Zou, and J. Stagg, "Robust latching MEMS translation stages for micro-optical systems," J. Micromech. Microeng., vol. 14, no. 5, pp. 667-674, May 2004.

[15] M. Ehmann, P. Ruther, M. von Arx, and O. Paul, "Operation and shortterm drift of polysilicon-heated CMOS microstructures at temperatures up to $1200 \mathrm{~K}$, J. Micromech. Microeng., vol. 11, no. 4, pp. 397-401, Jul. 2001. 
[16] J. Lee, T. Beechem, T. L. Wright, B. A. Nelson, S. Graham, and W. P. King, "Electrical, thermal, and mechanical characterization of silicon microcantilever heaters," J. Microelectromech. Syst., vol. 15, no. 6, pp. 1644-1655, Dec. 2006.

[17] R. Hickey, D. Sameoto, T. Hubbard, and M. Kujath, "Time and frequency response of two-arm micromachined thermal actuators," J. Micromech. Microeng., vol. 13, no. 1, pp. 40-46, 2003.

[18] D. R. Lide, Handbook of Chemistry and Physics, 87th ed. Boca Raton, FL: CRC Press, 2006

[19] Y. Okada and Y. Tokomaru, "Precise determination of lattice parameter and thermal expansion coefficient of silicon between 300 and $1500 \mathrm{~K}$," J. Appl. Phys., vol. 56, no. 2, pp. 314-320, Jul. 1984.

[20] A. F. Mills, Basic Heat and Mass Transfer, 2nd ed. Upper Saddle River, NJ: Prentice-Hall, 1999.

[21] N. D. Mankame and G. K. Ananthasuresh, "Comprehensive thermal modeling and characterization of an electro-thermal-compliant microactuator," J. Micromech. Microeng., vol. 11, no. 5, pp. 452-462, Sep. 2001.

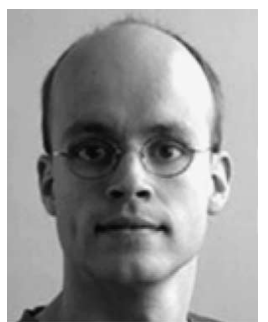

Vincent A. Henneken received the Graduate Mechanical Engineer degree with a specialization in production engineering from Delft University of Technology, Delft, The Netherlands, in 2002.

For his thesis, he worked on the design of a MEMS XY microstage for nanometer applications in a transmission electron microscope. This project was performed at the Philips Centre for Industrial Technology, Eindhoven, The Netherlands (later renamed Philips Applied Technologies). Since 2003, he has been with the Laboratory for Precision Manufacturing and Assembly, Delft University of Technology, as a Researcher to work toward his Ph.D. degree, where he develops MEMS-based electrothermal microactuator devices for the purpose of optical fiber-chip coupling.

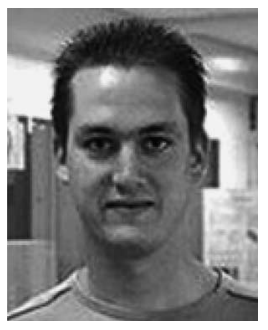

Wouter P. Sassen received the M.Sc. degree in mechanical engineering from Delft University of Technology, Delft, The Netherlands, in 2007, focusing on the design and finite element modeling of the improved positioning actuator.

He is currently a Researcher with the Laboratory for Precision Manufacturing and Assembly, Delft University of Technology, where he performed experiments on MEMS-based positioning and clamping devices, designed for optical fiber-chip coupling.

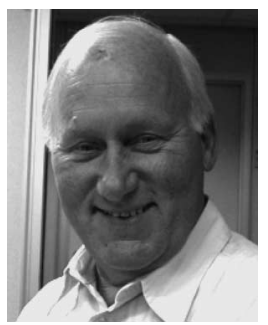

Wim van der Vlist was born on June 9, 1948. He received the Mechanical Engineering degree from the LTS and the MST (lower and intermediate technical schools).

In September 1964, he joined the Service Group of the Department of the Electrical Engineering, Delft University of Technology, Delft, The Netherlands. Since 1987, he has been a member of the IC Process Group of Delft Institute of Microsystems and Nanoelectronics, Delft University of Technology, where he is currently working on silicon IC and sensor processing. He is responsible for back end, wet chemical processing, and furnace for wet and dry oxide layer deposition and characterization.

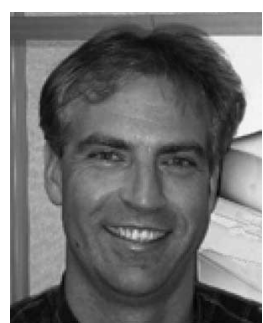

Wim H. A. Wien was born on July 21, 1964. He received the Chemical Processing Technology degree from the MST (intermediate technical school), Arnhem, The Netherlands, in 1985.

In 1988, he joined MOS 3 Fab-Philips Nijmegen as a Shift Engineer. From 1994 to 1999, he was an Assistant Process Engineer with the PAD-C pilot plant of AKZO Nobel, Arnhem, working on silicon and polymer-based optical switches. In 1999, he moved to JDS Uniphase Photonics production Fab, Arnhem, where he was an Assistant Process Engineer and a Supervisor Production Manager. Since August 2001, he has been a Process Engineer with the IC Process Group of Delft Institute of Microsystems and Nanoelectronics, Delft University of Technology, Delft, The Netherlands, where he is responsible for silicon IC and sensor processing, particularly for electrodeposition and spray coating of photoresists.

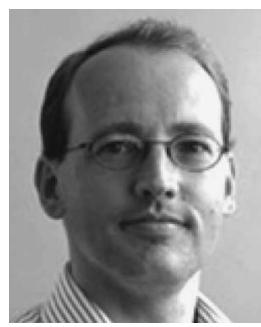

Marcel Tichem received the M.Sc. and Ph.D. degrees in mechanical engineering from Delft University of Technology, Delft, The Netherlands, in 1991 and 1997, respectively.

As an Associate Professor, he has initiated and is responsible for research in the domain of microassembly and packaging within the Laboratory for Precision Manufacturing and Assembly, Faculty of Mechanical, Maritime and Materials Engineering, Delft University of Technology. He is Associate Director of the Delft Centre for Mechatronics and Microsystems, an interfaculty program which aims to integrate the domains of mechanical engineering and microsystems. His research interests include micropart handling, application of microsystems for improved assembly possibilities, and assembly and packaging of hybrid microsystems.

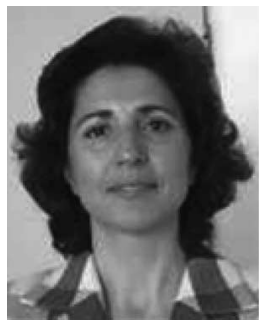

Pasqualina M. Sarro (M'84-S'84-SM'97-F'07) received the Laurea degree (cum laude) in solidstates physics from the University of Naples, Naples, Italy, in 1980, and the Ph.D. degree in electrical engineering from Delft University of Technology, Delft, The Netherlands, in 1987. Her thesis focuses on infrared sensors based on integrated silicon thermopiles.

From 1981 to 1983, she was a Postdoctoral Fellow in the Photovoltaic Research Group of the Division of Engineering, Brown University, Providence, RI. Since then, she has been with the Delft Institute of Microsystems and Nanoelectronics, Delft University of Technology, where she is responsible for research on integrated silicon sensors and MEMS technology. In December 2001, she became A. van Leeuwenhoek Professor and since 2004, she has been the Head of the Electronic Components, Materials and Technology Laboratory, Delft University of Technology. She has authored and coauthored more than 300 journal and conference papers.

Dr. Sarro received the EUROSENSORS Fellow Award for her contribution to the field of sensor technology, in 2004. In April 2006, she became member of the Dutch Royal Academy of Science and in November 2006, she was elected IEEE Fellow. She acts as Reviewer for a number of technical journals and she is a technical program committee member for several international conferences (IEEE MEMS, IEEE Sensors, Eurosensors, Transducers). 